\title{
Improvements to Student Learning Through Multidisciplinary Perspectives Reviewed from the Dimensions of Analytical Psychology
}

\author{
Chandana Watagodakumbura ${ }^{1, *}$ \\ ${ }^{1}$ School of Electrical and Computer Engineering, RMIT University, Melbourne, Australia \\ *Correspondence: School of Electrical and Computer Engineering, RMIT University, \\ Melbourne, Australia. E-mail: chandana.watagodakumbura@rmit.edu.au
}

Received: May 27, 2014 Accepted: July 4, 2014 Published: July 28, 2014

doi:10.5296/ije.v6i3.5696 URL: http://dx.doi.org/10.5296/ije.v6i3.5696

\begin{abstract}
In this paper, we look at some previously presented improvements to student learning through multidisciplinary perspectives (Watagodakumbura, 2012, 2013a, 2013b) from the viewpoints of analytical psychology. Diverse psychological and neurological student characteristics presented are evaluated from the viewpoints of psychological types presented in analytical psychology. Deep or higher-order learning is paralleled with the phenomenon of enhancing conscious sphere in which contents from the unconscious are brought to consciousness. Feeling and intuition psychological types are inferred to play an important role in this regard. Further, feeling and intuition conscious functions are identified to involve significantly when abstract concepts are learned and hence take relatively a longer time. The process of enhancing the conscious sphere directs individuals towards higher levels of human development. Developing creative instincts of learners through higher-levels of human development is inferred to be achieved only by allowing learners to undergo a complete, balanced learning cycle in which all conscious functions of sensing, thinking, feeling and intuition are given due attention. That is, both dominant and inferior functions play important roles.
\end{abstract}

Keywords: analytical psychology, higher-order learning, psychological characteristics, neurological characteristics, learner motivation, assessment 


\section{Introduction}

The main contribution of this paper is the review of some of the broader pedagogical practices suggested viewing them from disciplines such as psychology and neuroscience (Watagodakumbura, 2012, 2013a, 2013b) from the viewpoints highlighted in analytical psychology. Consequently, to start with, we give below an introductory summary as to what analytical psychology is all about. The reviewed improvements to student learning are presented subsequently in section 2 .

\subsection{Analytical Psychology: Main Concepts}

Analytical psychology is a sub-stream of the main discipline of psychology founded by the Swiss Psychiatrist and psychotherapist Carl Gustav Jung, in the early twentieth century. Consequently, analytical psychology is also known as Jungian psychology. Jung is a student of the famous Austrian neurologist Sigmund Freud, who became known as the founding father of psychoanalysis. In the last 2-3 decades, Jungian psychology is becoming more and more popular among practitioners of psychology, other philosophers and academics due to its versatility in other applications as well. Some basic concepts used in analytical psychology such as conscious/unconscious, psychological types, the shadow, the self and archetypes are introduced below.

\subsubsection{Conscious/Unconscious (Hauke, 2006)}

Human psyche is divided into conscious and unconscious parts. Consciousness grows out of the unconscious psyche. Ego is the centre of consciousness. Unconscious is divided further into personal unconscious and collective unconscious. Personal unconscious is acquired through lifetime through personal learning and experience. It occurs through repression, forgotten and sense-impressions that never had sufficient intensity to reach consciousness. On the other hand collective unconscious is the general, universal part, derived through aeons of repetitions of human cultural imagery and experience. These contents have never been conscious and owe their existence to a form of heredity. Further, they are identical in all individuals. That is, they are primordial images or records of the psyche of humankind going back to remotest beginnings. The process referred to as individuation integrates the conscious and unconscious psyches helping individuals to reach humanistically to full potential.

\subsubsection{Psychological Types (Beebe, 2006)}

Four functions of consciousness, namely, thinking, feeling sensing and intuition are introduced. Thinking and feeling are identified as rational functions and are situated at the opposite poles while sensing and intuition are identified as irrational functions that are situated at the opposite poles. Sensing is the conscious function that registers reality as real. Thinking is the function that defines what we perceive. Feeling is the function that assigns a value to what we have perceived. Intuition is the function that defines the implications and/ or possibilities of the thing that has been perceived empirically. In addition to having an inclination towards one or more of these functions, an individual will also have a more inclined attitude type, so to speak; the two possible attitude types Jung presented are introversion and extroversion. As long as a function is undifferentiated, it cannot be deployed 
in the conscious manner of a directed mental process. Individuation is the progressive differentiation of the various psychological functions of consciousness.

\subsubsection{The Self (Colman, 2006)}

The self is the centre of the psyche as well as the totality- sum total of conscious and unconscious contents- of the psyche. Thus, the self represents the psychic wholeness and is the goal towards which the individuation process strives. The individuation process resolves the state of inner conflict and opposition into a union of opposites which brings about wholeness. The self is the supra-ordinate or supra-personal centre of the personality and Jung regards God-images as the symbolic representation of the self.

\subsubsection{The Shadow (Casement, 2006)}

The shadow is complementary to consciously held attitudes and can be both personal and collective. The personal shadow may be conceived of as the repository of all the aspects of a person that are unacceptable or distasteful (envy, aggression, greed, laziness, jealously, shame) to them. The individuation process starts off by the individuals becoming conscious of their shadow, which can be painful although there is a gain. That is, to acquire self-knowledge one has to tackle the shadow. It is important to embodying the shadow in consciousness; otherwise, if it is repressed and isolated from consciousness, it remains uncorrected and liable to erupt in a moment of unawareness. Further, the inferior conscious function is equated with the shadow. When the shadow results in neurosis it becomes a necessity for the individual to find a way for the conscious personality and shadow to live together; instead of neurotic dissociation, one needs to struggle with it. Neurosis, according to Jung, is a state of being at war with oneself; what drives individuals to this state is the suspicion of being two people in opposition to each other - the shadow and the ego. Recognition of the shadow leads to humility and genuine fear of what lies in the depths of humanity.

\subsubsection{The Archetypes (Stevens, 2006)}

Jung maintained that there existed an additional phylogenetic layer (the collective unconscious) which incorporated the entire psychic potential of humankind. That is, human beings are born with the virtual images or archetypes such as parents, wife, children, birth and death etc. as psychic aptitudes. These images lack in solid content, and hence are unconscious.

\section{Analytical Psychology Viewpoints of Suggested Improvements to Student Learning}

\subsection{Addressing Unique Psychological and Neurological Needs of Learners}

We have seen a trend in the recent past that educational organisations promote inclusive practices to be applied to teaching-learning environments. At the same time, psychologists who study the characteristics of gifted personnel promote special educational programs and learning environments for gifted learners (Silverman, 1998, 2002). As revealed in studies 
with enough evidence, gifted personnel show overexcitabilities, namely in the areas of emotional, intellectual, imaginational, psychomotor and sensual (Dabrowski, 1970, 1972, 1977). These overexcitable characteristics make them react differently or in unusual manner to external stimuli or social situations than that would happen normally. For these individuals, overexcitable characteristics and behaviour are innate and natural to them and usually last throughout the life span. In our current practices, we tend to accept behaviours without overexcitable characteristics as the normal or expected average behaviour (Sylwester, 1998). We, as a society, tend to see those overexcitable characteristics and behaviour negatively, possibly as abnormal, despite the fact that individuals possessing these characteristics have the potential to be grate creators, innovators, leaders and scientists, to name a few, if fostered appropriately. From the viewpoints of analytical psychology, individuals possess different psychological types, namely sensing, thinking, feeling and intuition. Out of these four psychological types, gifted individuals are more likely to possess feeling and intuition types (Watagodakumbura, 2014). These are the two psychological types that are more likely to tap the unconscious of an individual. Consequently, gifted individual can be identified as those who are more likely to bring the contents from the unconscious to conscious, thus demonstrating more creative behaviour. They would bring to consciousness relatively unusual relationships that others wouldn't usually do. They are more likely to understand the reality as is, at times in uncommon ways, leading them to higher levels of human development with an enhanced conscious sphere.

The trend in the recent past promoting inclusive practices has not gone much far; the current superficial level of these practices need to go beyond this level to enhance broader understanding and acceptance. How would the above characteristics of higher levels of consciousness and intuition of gifted individuals be correctly identified and supported in an education system? This is a challenge we face in building fairer societies. The current trend in our educational practices is that these vital traits in terms of human development go unnoticed or undetected. The author does not believe that disintegrating gifted personal from the mainstream education system is a viable solution; rather it should be including them in the mainstream system provided that inclusive practices are broadly and deeply understood and practiced. In a better educational system, one of the most important features is to raise the awareness of neurological and psychological diversity within the human species. We are made aware of each other's differences and we become more tolerant and accepting. It is quite natural that we tend to see clones of ourselves in the people we meet and disregard highly possible psychological and neurological difference in two different individuals. In a better education framework we attempt to address this limitation directly and squarely (Watagodakumbura, 2013a, 2013b). We inquire, especially, about possible emotional, intellectual and imaginational overexcitable characteristics of some learners that impact their learning process, and we accept that we need to make allowances for them. Individuals possessing these overexcitable characteristics tend to be curious, inquiring, creative and open-minded and yearning for fulfilment of these instincts. Further, they have an enhanced conscious sphere and capable of tapping the unconscious better through intuition in analytical psychological terms; they are capable of seeing unusual relationships in the knowledge they get exposed to. In other words, how can we engage in our teaching-learning process so that 
such individuals are not disadvantaged and identified correctly? How can we construct curricular to meet the needs of these personnel with overexcitable characteristics? As suggested in an authentic education framework (Watagodakumbura, 2013a, 2013b), learner evaluations can be done using generic attributes, rather than the currently used subject area specific grade or numeric mark. One possible generic attribute would be how well a learner can see new relationships intuitively in the knowledge or area exposed to. The positives of using generic attributes is that it is associated with the intrinsic learner characteristics and valid possibly throughout his or her life span; on the other hand, giving a numeric mark to an area of study has an extrinsic nature and may be valid for a shorter period of time after the conduction of the assessment. If we can identify an individual with intellectual, imaginational and emotional overexcitable characteristics, and are aware of his or her potential, the probable employers can match his or her intrinsic abilities and skills to an appropriate employment category. In this situation, the individual will be at ease or in equilibrium with his internal psychological and neurological characteristics and the employer benefiting from a highly functioning, well-tuned employee.

\subsection{Non-Existence of Idealistic Learners in Learning Environments}

The characteristics of learners can be broadly categorised in to two, either visual spatial or auditory sequential (Silverman, 2002). When we differentiate between the two categories, it is important to understand that when one possess stronger characteristics in one type, he or she is most likely to distant himself or herself from the other type. For example, if one possesses much stronger visual spatial characteristics, he or she may show reduced competencies in auditory sequential skills. However, in learning environments, we tend to expect idealistic individuals possessing strong characteristics of both visual spatial as well as auditory sequential. The author argues that such expectations could be unrealistic. From the viewpoints of analytical psychology, the two rational psychological types or conscious functions thinking and feeling are situated at the opposite poles. Similarly, the two irrational psychological types sensing and intuition are at the opposite poles. As a result, if an individual possesses a certain rational or irrational psychological type as the dominant conscious function, the ones at the opposite poles are referred to as the inferior or weaker conscious functions. That is, it is highly unlikely that an individual possess the conscious functions at the opposite poles as the dominant functions. In other words, it is we being idealistic to expect a highly sensitive person with imaginational, intellectual and emotional overexcitabilities to be easy going and extroverted; it is highly possible that such a person is an introvert. It is as if we are expecting someone with very good abstract thinking abilities to be good at memorising facts or rote learning at the same time; gifted learners with good abstract thinking abilities perform much badly in rote learning environments. It is as if we are expecting a highly intuitive individual who relates to his or her unconscious well to be equally good in the sensing function and dealing relatively well with environmental stimuli. As a better educational practice, we tend to differentiate learners possessing a more preferred style, while trying to help learners on improving in the other style, without disregarding the less preferred one outright. Further, in analytical psychology, it is highlighted that when one engages in human development to higher levels as referred to in the concept of self, it is 
essential that he or she deals directly with his or her inferior conscious functions as well. Getting the two opposite functions to agree is a highly difficult task and is referred to as the union of opposites.

\subsection{Focus on Higher Order Learning in a Practical Sense}

The focus of learning, irrespective of the discipline or area of study, needs to be beyond pure memorisation of facts or information. By memorising, we commit facts or information to our short-term memory. Just because we encounter situations in our day to day lives that we can make use of memorisation of facts usefully, we cannot justify it being used as the focus for learning in many educational environments. We see education more broadly, something that helps individuals to reach their authentic or unique full potential, maximising the level efficiency of their social operations. When we try to understand what higher-order learning is, Bloom's taxonomy is a very useful tool to employ digesting it (Biggs, 2003; Entwistle, 1998; Laurillard, 2002). At the lower end of the spectrum we have remembering and mere comprehension and at the higher end of the spectrum we have synthesis and evaluation; in the middle level, we have application and analysis of knowledge. Looking at this classification from an analytical psychology viewpoint, we can infer that the lower-end tasks are usually associated with sensing and thinking psychological types by definition while the tasks at the higher-end essentially need to use the feeling and intuition psychological tasks. We get to see yet again the significance of focusing on higher-order learning as it essentially makes use of the feeling and intuition conscious functions. By doing this, we are able to enhance the conscious sphere of learners that leads to higher levels of human development. In other words, when we encourage learners to engage in tasks of synthesis and evaluation, we lead them on a path to deliver creative outputs by taping their unconscious.

Though most of us understand the essence of Bloom's taxonomy, there might be significant differences in the way we apply it to learning and assessment. One common understanding would be that we can use the lower end of the spectrum for relatively lower years of learning while the higher end of the spectrum for higher years of learning. For example, for undergraduate students, we may use a lower level of the classification and for postgraduate students we may use the higher end. In other words, from the viewpoints of analytical psychology, we may focus on sensing and thinking psychological types when teaching undergraduates while concentrate on feeling and intuition psychological types when teaching postgraduate students. The author argues that this is an incorrect simplification, and for all years or levels, we need to focus mainly on the highest end of the spectrum or feeling and intuition psychological types even though we may make use of the other levels of the full spectrum in combination. That is, at any year or level, we may have learners who would like to get the comfort of the lower as well as higher level of the spectrum, for various reasons; our duty, as educators, should be to push everyone towards following higher end practices, and thereby for higher order learning. We also have to use the Bloom's taxonomy as a tool for identifying intrinsic learner characteristics, but not just to discriminate one end at the expense of the other. In the section highlighting the balance of practical work and theory in a learning environment, we point out the significance in practical work even though on Bloom's spectrum it may fall towards the lower end; in a practical work session, we may 
mostly follow some instruction to accomplish a task and may not have engagements related to synthesis and evaluation. But we engage in practical work in a learning environment to enhance our understanding of abstract theories. We also point out that assessment on practical work may even be of formative type. To recall, we have both auditory sequential and visual spatial learners. We accept their unique contributions to our social operations; the balance of the society is maintained due to the unique operations of all categories. However, in a learning environment, we attempt to give mixed exposures to all learners; that is if an individual is identified to prefer a learning context highlighting lower end of the spectrum, we encourage them to take special measures in practising learning contexts at the higher end of the spectrum; we do this because it will be useful for an individual to develop skills pertaining to both ends of the spectrum, in their social operations. From an analytical psychology point of view, we encourage learners to focus on the dominant conscious function while paying enough attention to the inferior conscious functions as well. To achieve a higher level of human development, it is essential that an individual see the union of opposites or dominant and inferior functions.

Another limitation of our current practices is that we tend to set a lower ceiling of the spectrum to our learning and assessment environment. That is, we may focus on analysis or application as the highest possible level in teaching-learning practices, disregarding higher levels of synthesis and evaluation. In any arbitrary learner cohort, we may have learners with characteristics preferred to either higher end of the spectrum or lower end of the spectrum; if we set a ceiling at a middle level, we are disregarding some learner category. For example, we may not address the needs of individuals who have preferred psychological types of feeling and intuition, form the viewpoint of analytical psychology. This is something we are trying to avoid in a better education framework; we endeavour to give every learner an opportunity to develop their authentic characteristics, to make them at ease with their natural innate psychological and neurological characteristics. We also have a common inclination to assume that the highest end of the spectrum, namely synthesis and evaluation tasks, can only be applied to research education; the author argues that this is really not the case as we can look for creative answers learners provide especially for open-ended question we use for assessment. Further we can encourage and provide an appropriate environment for learners to develop open-minded thinking in the learning process and to provide authentic or unique and creative solutions to possible open-ended questions we set. By encouraging open-minded thinking, we put learners on a path to tap their unconscious and bring its contents to the conscious, in an analytical psychology point of view. Despite our inclination to accept relative difficulty on conducting courses in hard science areas with a focus of enhancing learner creativity, the author argues we still can achieve that on a properly set and focused curriculum.

\subsection{Giving Special Attention to Time Factor on Learning}

In our current practices, one of the most common limitations would be not giving enough attention to the time factor, irrespective of whether it is on assessment or whole teaching-learning process. One significant point we need to highlight here is that human brain or neural system is a parallel processor. It takes in a large number of inputs and attempts to 
recognise patterns in a learning process based on feedback cycles to produce the output. This process usually takes more time than serial processing in which relatively a less number of inputs is taken in, send them through a number of repetitive processing cycles rapidly, before producing the output that is very precise in nature; typical computers or machines operate in the latter manner (Beale and Jackson). We tend to disregard this significant difference in how human brains operates and how typical computers or machines operate in our practices in teaching-learning; in our teaching learning environments we need to provide enough time for human brains to absorb information and engage in a learning process by constructing meaning, before giving the output. For this construction of meaning process, information would be gathered from different parts of the brain utilising a reasonable amount of time. For this very reason it is important to use a dialectic approach ahead of didactic approach in a teaching-learning environment. We allow and encourage learners to construct personalised meaning in a learning process, considering all the inputs they take in, rather than merely committing to short term memory. We need to provide as many related and useful inputs as possible along with adequate time for learners to construct meaning and produce a lasting learning outcome. From the viewpoints of analytical psychology, we can infer that feeling and intuition conscious functions play an important role in the above construction of meaning process. We can infer that compared to sensing and thinking conscious functions, feeling and intuition functions utilise relatively more time, verifying the need of an adequate time for the learning process. We can direct human brains to focus on what they are good at doing and get typical computers or machines to do what they are capable of, with a clear distinction. There is no benefit in trying to force human brains to emulate machines in the face of process automation tasks that make routine human labour redundant, a trend observed in the recent past.

In a similar manner, when assessing student learning, we need to provide them enough time to construct the solution based on the given number of inputs. We are stressing here the point that the assessment we mention is not based on mere recalling facts; recalling facts can probably be done rapidly, if they are committed to short term memory and the nature of the assessment requires such practice. Merely testing the learners' ability to recall facts would not constitute a proper assessment, or educational experience (Biggs, 2003; Ramsden, 2003). In contrast, learners can be presented with open-ended questions so that they will have to engage in a process of construction of meaning to provide an answer. From an analytical psychology point of view, learners will have to utilise feeling and intuition conscious functions consuming relatively a longer period of time. Also, when learners construct their answer, we need to give them enough time to write them down on the paper. If we do not give enough attention to these timing factors when setting up assessments, it is possible that learners perform badly in assessments not due to their lack of deep learning, but due to the way the assessment is structured. Even worse, some learner categories such as visual spatial learners tend to get more disadvantaged in these circumstances than others; they perform relatively badly on timed tests.

We can have another viewpoint on this timing factor in the following manner. Usually, if we keep on practicing the same thing for a longer period, we tend to improve on the time taken 
to complete it. Sometimes these improvements can be seen over many years. However, in a typical learning environment, learners take up a course for a period of a few weeks. They might be taking a few other similar courses in parallel as well, in a programme of study. Consequently, it is not appropriate for us to expect learners to reach a speed that would be demonstrated by one with years of repetitive experience. We have to be realistic in the speed, or the response time, in which learners could provide answers after a study of a few weeks. We highlighted this point here because it is not very uncommon that learners comment on insufficient time for completing an assessment in many teaching-learning environments.

\subsection{Giving Special Attention to Improving Learner Motivation Level}

Sometimes, the performance of learners is hampered due to lack of learner motivation level (Maslow, 1987). We will have learners who just need to get through a particular course with a pass or merely taking a course because there are no better alternatives; it may be that the particular course is not in their main interest list, or their focused career paths. Even we may not know how many of the learners taking a course would end up following a career path highlighted in the subject area. It is not uncommon that we get to hear from past learners about some of the courses they have undertaken, covering very narrow specific material, have never been used or being useful afterwards. Disregarding these facts, we may conduct courses in a narrow way, targeting more specific knowledge areas and applications. In general, we can increase the level of learner motivation by structuring a course with a focus to generalised or broader knowledge or concepts. Such generalised knowledge or concepts highlighted in any course would be more useful for learners in a general way, probably in learning other courses, in day to day life situations or in personal development. Also, such generalised knowledge or concepts will last longer in learner minds, increasing usefulness. To achieve this, we can relate the subject matter highlighted in a course to more generic applications or situation, rather than subject specific ones; then we can construct assessments having this focus in mind as the learners are usually guided by the assessment. From an analytical psychology point of view, by focusing on generic concepts, we are encouraging learners to tap their unconscious better. That is, the unconscious is the place where you find archetypes or skeletons of concepts going back to thousands of years stored. To reiterate, these archetypes are not detailed specific information, rather only the frameworks. By highlighting generic concepts, we help learners to reach out to these archetypal skeletons in the unconscious, thereby enhancing the conscious sphere. Since this process leads to a higher level of human development, learners would become more motivated when the underlying learning objectives are understood. That is, if the learners are convinced that a particular course would possibly help them in a more generic way, irrespective of their career or personal interests, they would be more motivated in investing their time to learn it. Generally, the higher the level of motivation, the more the effective time spend on learning it, possibly yielding better learning outcomes . Thus, as educators, it is now our responsibility to present contents in a more generalised manner, making them more useful in a wider range of applications. 


\subsection{Giving Special Attention to Designing Assessments Appropriately}

Current practices of education lead to a number of less optimal assessment related issues. Learners are usually directed by assessment in how they engage in the process of learning (Biggs, 2003; Ramsden, 2003). If assessments are conducted in order to test the ability to recall facts, learners would usually try to cram the facts in to their heads the night before the assessment or examination. If assessments lead to testing deeper understanding of the content covered, then learners would have no option but to study and understand the content spending more time throughout the period, possibly a semester or term. This is not to disregard the fact that, knowing mere facts would be very useful in many real life day-to-day situations. But the important point is, since facts can be relatively easily memorised or committed to short-term memory if a situation requires, it does not need to be practiced or the main focus in a course of education. With the technological advances in the last few decades, information or facts get to your table very easily and cheaply; what is important is to relate this information to other such information and personal experiences and make more useful deeper meaning or knowledge. Hundreds of years ago, when mere gathering of facts was difficult and expensive, memorising facts would have been a great achievement. From an analytical psychology viewpoint, we can infer that signifying memorisation of facts mean that we pay undue emphasis on sensing and thinking psychological conscious functions ahead of feeling and intuition functions. The result is that learners are not given the opportunity to reach out their unconscious and thereby not allowing them to traverse to a higher level of human development. Despite years of social and technological changes, we still have roots of assessment focusing recall of facts in a number of learning environments. We probably are giving in to years of traditional practices rather than being reflective on our practices.

The focus of assessments should be to evaluate how much generalised concepts or knowledge learners retain at the completion of a study period. In a process of generalisation, learners abstract the commonalities from a set of available specific information or knowledge. Such generalised concepts or knowledge can usually be retained for longer periods or committed to long-term memory and would be more useful in other areas of study or day-to-day life situations. It would be less ideal if we test learners for the ability to recall or apply specific or narrow knowledge for a specific application that may have learned during the study period. Learners tend to forget specific or narrow knowledge gained during a study period very soon, probably within days or weeks; they may succeed in recalling and applying knowledge in an assessment just after the study period, but not beyond that. To improve validity of assessments, our focus should be to test more generalised knowledge or concepts that learners can and will retain longer, possibly for months or years, and that would be useful more generally. In this way, we encourage our learners to engage in learning in such a way that they can relate what they learn to more general situations or applications, as that is the focus of assessment. From an analytical psychology point of view, we can pay more attention to feeling and intuition conscious functions when formulating assessment so that we get the opportunity to focus on general concepts.

Sometimes over a study period of a semester or term, we introduce a number of many new learning materials or concepts to our learners, spending a considerable amount of time, but 
focus of assessments could be restricted to only a few areas. In other words, assessments are not properly and fairly aligned to learning. Learners may have invested time on learning all areas presented, but would find that assessments are focused only on a few narrow areas or sections. We should try to avoid such situations as evaluation results may not reflect learner understanding accurately. We may also fail to get the attention of learners on some important sections of the subject, or may inadvertently direct them to learn strategically to purely get through assessments. Basically, we need to align assessments to learning properly. Ideally, we should construct assessment constituting material or sections in proportion to the time we utilise to introduce and make the learner understand the same. In this way, we tend to introduce the most important sections or concepts in the subject area, spend a reasonable of time on them in making learners understand and then follow it up with an evaluation in the assessment. This contrasts from setting up assessments from only the areas or sections preferred by the facilitator or the facilitator is more comfortable in setting up questions. These improved broader practices make assessment more consistent and fairer. Some learners with perfectionist attitudes, such as the visual spatial learners, will be disadvantaged if we are not consistent with the assessment material selection in regard to the time we spend on elaborating them; such inconsistencies direct learners to take a strategic learning approach, which is not the usual preference for visual spatial learners.

\subsection{Finding the Right Balance between Theory and Practice}

We have learning environments in which attention is not paid enough for finding a balance between the theory discussed and practical work attempted. Understanding theory usually requires good abstract thinking skills and practical work attempted should ideally help in deepening the understanding of the theory. In other words, the practical work attempted should be directly related to the theory discussed in a learning process. In a number of situations we may find that theory and practical work are two disjoint subsets. We should not fill a learning schedule with only somewhat related practical work that does not enhance the understanding of abstract theory. Usually practical work can be attempted by following step by step instructions or following a live demonstration, but understanding an abstract theory can be more absorbing. If we heavily load a learning environment with practical work with little theory, we may be imparting very narrow set of skills for a specific application. These skills might not be very useful in the longer run or in a different environment or application. We are not giving much attention to generalised knowledge or concepts that could be useful in the longer run or different situations. From an analytical psychology viewpoint, we have to essentially pay attention to feeling and intuition conscious functions in order to emphasise on high-level generalised concepts. That is, merely concentrating on sensing and feeling conscious functions in a teaching-learning environment will not be adequate. On the other hand, if we overload a learning environment with a large portion of theory with very little practical exposure, learners may find it hard to understand or digest the high level of abstract theory; they may find it difficult to use the theory discussed to other related areas of study or other applications. In the event that practical work cannot be undertaken in a laboratory environment due to various reasons, similar examples such as simulations and/or case studies can be put forth for learners to digest abstract concepts. Modern computer video and graphic 
applications provide immense promise in this regard. Participation in practical work may be ideally assessed as part of formative assessment, as mastery of practical skills usually requires longer times and repetition. However, abstract thinking skills related to theory need to be ideally assessed using summative assessment methods, as grasping of fundamental knowledge in any area of study is very important. It is important to understand that even though well-developed practical skills would yield employment for individuals, within a better framework, we see education in a broader sense, with better personal development on the whole, helping individuals to take better decisions, not only in professional lives, but also in day-to-day social operations. The significance of this balance between theory and practical work is highlighted in Kolb’s Experiential Learning Cycle (Kolb, 1983; Zull, 2002). In that, learning is completed in four cycles, namely, concrete experience, reflective observation, abstract conceptualisation and active experimentation. Concrete experience and abstract conceptualisation related to a certain learning activity plays the roles of two very important phases in the complete learning cycle. From the viewpoint of analytical psychology, it means that all four conscious functions sensing, thinking, feeling and intuition are important in accomplishing complete learning. Consequently, when we emphasise on the complete learning cycle, we encourage learners to pay attention to both dominant and inferior conscious functions. This will put learners on a path to a higher level of human development. A balance in theory and practice in an educational course would help both the visual spatial leaners and auditory sequential learners in getting a better understanding, rather than being biased towards one or the other category.

\section{Conclusion}

In this paper, a number of improvements to student learning suggested previously by looking at the broader concept of learning from a multidisciplinary perspectives were further reviewed from the viewpoints of analytical psychology. The improvements reviewed include giving due consideration to learners' neurological and psychological characteristics, focus on higher-order learning, giving special attention to time factor in teaching-learning, taking learner motivation levels into consideration and finding a balance between theory and practical work. The above improvements were reviewed from the main concepts of analytical psychology, namely, conscious/unconscious, psychological types, the self, the shadow and the archetypes. Interestingly, it was possible to use the theoretical background from analytical psychology to further support and justify each and every improvement considered previously. Despite being introduced a number of decades ago, the versatility of analytical psychology has begun to be recognised in a number of areas including education, as highlighted in this paper. Consequently, we were able to further broaden the existing pedagogical knowledge base from the dimensions of analytical psychology. 


\section{References}

Beale, R., \& Jackson, T. (1990). Neural Computing - An Introduction. Bristol:Institute of Physics Publishing. http://dx.doi.org/10.1887/0852742622

Beebe, J. (2006). Psychological Types. In R. K. Papadopoulos (Ed.) The Handbook of Jungian Psychology - Theory, Practice and Applications. Sussex, UK: Routledge.

Biggs, J. (2003). Teaching for Quality Learning at University ( $2^{\text {nd }}$ ed.). Buckingham:Society for Research into Higher Education and Open University Press.

Casement, A. (2006). The Shadow. In R. K. Papadopoulos (Ed.) The Handbook of Jungian Psychology - Theory, Practice and Applications. Sussex, UK: Routledge.

Colman, W. (2006). The Self. In R. K. Papadopoulos (Ed.) The Handbook of Jungian Psychology - Theory, Practice and Applications. Sussex, UK: Routledge.

Dabrowski, K. (with Kawczak, A. and Piechowski, M. M.). (1970). Mental Growth through Positive Disintegration. London: Gryf Publications

Dabrowski, K. (1972). Psychoneuroses Is Not An Illness. London: Gryf Publications.

Dabrowski, K. (1977). Theory of Levels of Emotional Development (vol 1) - Multilevelness and Positive Disintegration. New York: Dabor Science Publications.

Entwistle, N. J. (1998). Approaches to Learning and Forms of Understanding. In B. Dart \& G. Boulton-Lewis (Eds), Teaching and Learning in Higher Education, 72-101. Melbourne, Australia: Australian Council for Educational Research

Hauke, C. (2006). The Unconscious - Personal and collective. In R. K. Papadopoulos (Ed.) The Handbook of Jungian Psychology - Theory, Practice and Applications. Sussex, UK: Routledge.

Kolb, D. (1983). Experiential Learning: Experience as the Source of Learning and Development. USA: Prentice Hall.

Laurillard, D. (2002). Rethinking University Teaching (2 ${ }^{\text {nd }}$ ed.). London: RoutledgeFalmer. http://dx.doi.org/10.4324/9780203304846

Maslow, A. (1987). Motivation and Personality. Hong Kong: Longman Asia Ltd.

Ramsden, P. (2003). Learning to Teach in Higher Education( $2^{\text {nd }}$ ed.). London: RoutledgeFalmer.

Silverman, L. K. (1998). Personality and Learning Styles of Gifted Children. In Van Tassel Baska (Ed) Excellence In Educating Gifted \& Talented Learners (3 ${ }^{\text {rd }}$ ed), Denver, Colorado, USA: Love Publishing Company.

Silverman, L. K. (2002). Upside-Down Brilliance: The Visual-Spatial Learner. Denver: DeLeon Publishing.

Stevens, A. (2006). The Archetypes. In R. K. Papadopoulos (Ed.) The Handbook of Jungian 
Psychology - Theory, Practice and Applications. Sussex, UK: Routledge.

Sylwester, R. (1998). The Downshifting Dilemma: A Commentary and Proposal. New Horizons for Learning: School of Education, Johns Hopkins University. Retrieved from http://education.jhu.edu/newhorizons/Neurosciences/articles/

Watagodakumbura, C. (2012). Improving Student Learning through Multidisciplinary Perspectives. Journal of Teaching and Education, 1(5), 261-267.

Watagodakumbura, C. (2013a). The Need for a Deeper Perspective of Education to Make Way for an Authentic Learning Experience. Journal of Education and Learning, 2(4), 31-39. http://dx.doi.org/10.5539/jel.v2n4p31

Watagodakumbura, C. (2013b). Education from a Deeper and Multidisciplinary Perspective - To a Sustainable Development of a Neurodiverse Society-A Futuristic View. USA: Xlibris.

Watagodakumbura, C. (2014). Authentic Education, the Deeper and Multidisciplinary Perspective of Education, from the Viewpoint of Analytical Psychology. World Journal of Education, 4(3), 19-28. http://dx.doi.org/10.5430/wje.v4n3p19

Zull, J. E. (2002). The Art of Changing the Brain: Enriching the Practice of Teaching by Exploring the Biology of Learning. USA: Stylus Publishing.

\section{Copyright Disclaimer}

Copyright reserved by the author(s).

This article is an open-access article distributed under the terms and conditions of the Creative Commons Attribution license (http://creativecommons.org/licenses/by/3.0/). 